\title{
Model Design and Strategy for Integrated Management and Control of Enterprise Risk
}

\author{
Meixia JIANG \\ Shandong Aerospace Electro-technology Institute, Yantai 264670, China
}

\begin{abstract}
Integrated management and control of enterprise risk is not strictly a serial process that is made beforehand, it will be adjusted as the situation and environment changing. This paper develops an analytical model for integrated management and control of enterprise risk. In this model, disclosures provide information about firm value to future investors. A key feature of the model is that the hierarchical functional structure referred to as "tiers" is draw-out for identification and assessment of enterprise risk. And the process of enterprise risk management and control is derived. Integrated management and control of enterprise risk is not strictly a serial process that is made beforehand, it will be adjusted as the situation and environment changing. This paper develops an analytical model for integrated management and control of enterprise risk. In this model, disclosures provide information about firm value to future investors. A key feature of the model is that the hierarchical functional structure referred to as "tiers" is draw-out for identification and assessment of enterprise risk. And the process of enterprise risk management and control is derived.
\end{abstract}

KEYWORD: Model Design; Enterprise Risk; Management and Control

\section{INTRODUCTION}

Nowadays, business world is ceaselessly changing it's unpredictable, gusty, volatile, and seems to become more complex ever and again. By the order of nature, enterprise is influenced by various events. Events can have negative influence or positive influence on the achievement of enterprise objectives. Events with a negative impact represent risks, which can prevent value creation or erode existing value. Events with positive impact may offset negative impacts or represent opportunities. Opportunities are the possibility that an event will occur and positively affect the achievement of objectives, supporting value creation or preservation. [1]

The Institute of Internal Auditors defines risk as "...the uncertainty of an event occurring that could have an impact on the achievement of objectives. Risk is measured in terms of consequences and likelihood.'[2] By the reason of risk existing everywhere of enterprise, it is almost impossible to evade all risk completely. Even though all the risk can be eliminated, the enterprise can't endure the cost should be paid out. Enterprise risk management is the action of operation risk management that places a greater effect on cooperation among sections to manage the enterprise's full range of risks as a whole.

For enterprise risk management, there are several important points that have driven the requirement, such as greater transparency, financial disclosures with more strict reporting, policy continuity and information integrity. Enterprise risk management provides an approach for effectively managing uncertainty, responding to paroxysmal event occurred with complex influence, enhancing quality and throughput, reducing losing and harnessing opportunities as they arise.

Usually, enterprises have treated risk as a necessary disaster which should be avoided, reduced or mitigated whenever possible. Recently, increased variational demands have forced enterprises to spend plentiful resources to deal with different possible risks.

\section{IDENTIFICATION AND ASSESSMENT OF RISK}

Identification and assessment of risk are systematic approaches to evaluate and identify different factors that maybe influence the achievement of enterprise, positively or negatively. Such factors may come from the external environment (e.g., economic 
condition, evolution posture, macro-policies, exchange rate and competition) or within an enterprise's internal environment (e.g., resource, process, management, operation and infrastructure). When these factors intersect with an enterprise's objectives - or can be predicted to do so-they will become risks.

To limit the damage of different risks, these factors should be conducted at different levels of the enterprise, i.e. risk identification, measurement and assessment. All the risks can be placed in a hierarchical functional structure referred to as "tiers". This is implemented in the model of risk management and control, by grouping the risks into three tiers called the strategic-level risks, the business-line level, and project-level risks.

Strategic-level risks relate to the enterprise's mission and strategic objectives, and include operational, financial, credit, stakeholder, internal audit, reputation, credit, legal and compliance, fraud, and business performance and continuity risks. Strategic risks are identified by monitoring and measuring at both the strategic and business-line levels.

- Operational risk. Business processes risks, resulting from inadequate or failed internal processes, resource, implement and infrastructures, or resulting from external events.

- Financial risk. Risks related to a material misstatement of the enterprise's financial statements through input from various parties.

- Internal audit risk. Risks related to the value drivers of the enterprise, covering strategic, financial, operational, and compliance objectives.

- Fraud risk. Potential instances of fraud that could impact the enterprise's ethics and compliance standards, business practice requirements, and other objectives.

- Credit risk. Potential that a borrower or counterparty will fail to meet its obligations in accordance with agreed terms.

- Market risk. Market actions that could affect the enterprise's performance or risk exposure, considering interest rate risk, currency risk, and option risk.

- Security risk. Potential breaches in an enterprise's physical assets and information protection and security.

Business-Line level risks are monitored and assessed by business-line management groups, and include customer, supply, and product risks. These risks are resistances for enterprise to meet anticipate targets and realize business objectives.

- Customer risk. Risk profile of customers that could potentially impact the enterprise's reputation and financial position.

- Supply chain risk. Risks associated with identifying the inputs and logistics needed to support the creation of products and services.
- Product risk. Risk factors associated with an enterprise's product, from design and development through manufacturing, storage, distribution, use, and disposal.

Project-level Risks are factors associated with the delivery or implementation of a project, considering stakeholders, dependencies, timelines, cost, and other key considerations. These risks imperil the range, rate of progress, cost, quality and function of agency projects, which are identified by project top level managers.

Enterprise accomplishes its objectives by management and control risk at three levels. Figure 1 shows the alignment of risks at the three tiers.

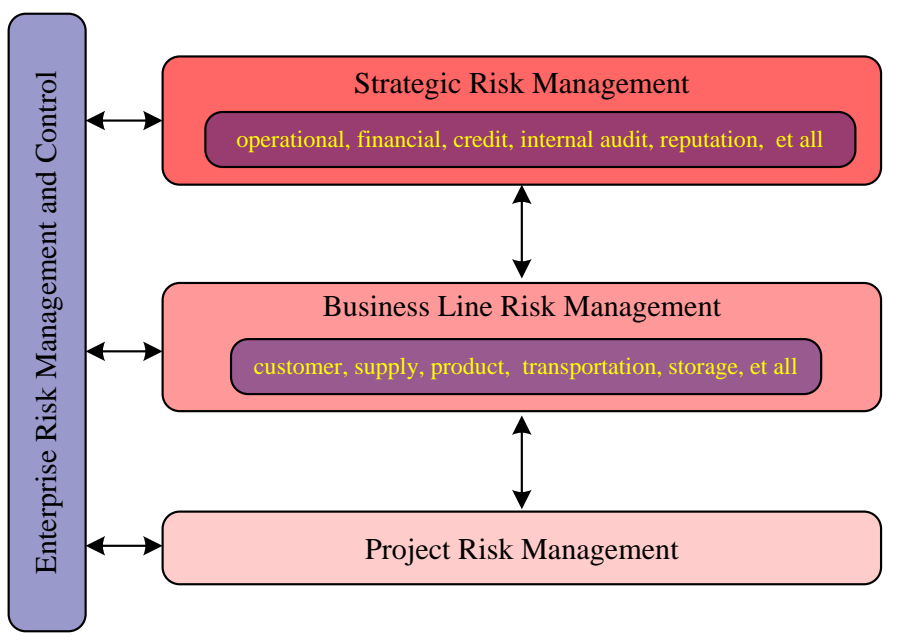

Fig. 1: Alignment of risks at the three tiers

Risk identification and assessment provide a method for identifying which risks bring opportunities or potential pitfalls. Since this work is very important to a corporation, each enterprise should develop its specific risk assessment step. Any risk identification and assessment exercise should establish a scope and plan firstly. There are some complications should be considered in the risk identification and assessment process, such as enterprise objectives, responsibilities, project function, timing, framework, and input and output requirements. Responsibilities are assigned to those managers who can provide meaningful view on related risks, and ensure that the treatment action is implemented effectively. Sources of input are determined according to available different information. Output requirements are established in accordance with the specific requirements of stakeholders.

\section{MANAGEMENT AND CONTROL OF ENTERPRISE RISK}

Enterprise risk management and control treating risks and opportunities which influence the achievement of enterprise's business objectives can be defined as follows: 
Enterprise risk management is a process, effected by an entity's board of directors, management and other personnel, applied in strategy setting and across the enterprise, designed to identify potential events that may affect the entity, and manage risk to be within its risk appetite, to provide reasonable assurance regarding the achievement of entity objectives. [3]

The above definition of enterprise risk management reflects some essential concepts are specified as follow:

- Risk management is a process applied through an organization at every level, such as entity level, department level and unit level.

- The affection may be influenced by members at different position and environment of an enterprise.

- This process carries out throughout enterprise business action all the time.

- Applied in strategy establishment that will be accomplished and represents the methods by which end-intentions are achieved.

- Proposed to identify possible events that maybe influence the entity.

Enterprise risk management consists of different correlative elements. These are derived from the approach management operates an enterprise and are integrated with the management method. These elements are:

- Objective making - Internal environment such as rules for how risk is viewed and addressed, risk management philosophy and risk appetite should be considered firstly in enterprise risk control objectives establishment process. Objectives must exist before management can identify the risks that are potential events affecting the enterprise achievement.

- Identification - Internal and external events affecting achievement of the enterprise's objectives must be apperceived, identified, distinguishing between risks and opportunities.

- Analysis - Different risks are analyzed by considering likelihood and impact, as a basis for determining how and what they should be managed. Risk analysis can be carried out by using simple approaches to depict multifarious risks, such as probability and impact matrices, or more sophisticated probabilistic methods, such as threepoint estimates or probability functions and Monte Carlo simulations[4-6].

- Response - There are some different risk responses can be selected by management, such as avoiding risk, accepting risk, reducing risk, or transferring risk. If risk avoidance doesn't affect the realization of enterprise objective, it is the best option. Risk reducing typically involves making an investment to decrease the consequence or likelihood of a risk. The fundamental tenets of risk transference include allocating risks to the party best able to manage them, allocating risks in alignment with agency goals, and allocating risks to promote team alignment with customer oriented performance goals.[7] If the risk response strategy is ascertained, then a set of actions to align risks with the entity's risk tolerances and risk appetite should be developed.

- Monitoring - Risk monitoring and review are the capture, analysis, and reporting of risk status in relation to response and treatment process. Monitor and control via a process for tracking a treatment process as it's executed, detecting problems or changes in its underlying premises, and reporting to appropriate management levels.

As shown above, once the tiers and scoping are established, the risk identification, measurement, assessment and management process can be implemented as the Figure 2.

There is a direct relationship between organization objectives and enterprise risk management elements. The defining, quantitatively or qualitatively of a risk is given by the application of more qualitative methods. Risks are assessed on an inherent and a residual basis. Rules and treatment procedures are established and carried out to help guarantee the risk responses are applied effectively. The entirety of enterprise risk management is monitored and modifications made as necessary.

Enterprise objectives analysis:

Action to comprehend enterprise objectives

Risk identification:

Process of finding, recognizing, and describing factors that may influence the realization of objectives.

\section{Risk analysis :}

Process to understand the nature of risk, determine the level of risk, and analyse risk tolerant.

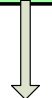

Influence analysis:

Assess likelihood and impact of risks.

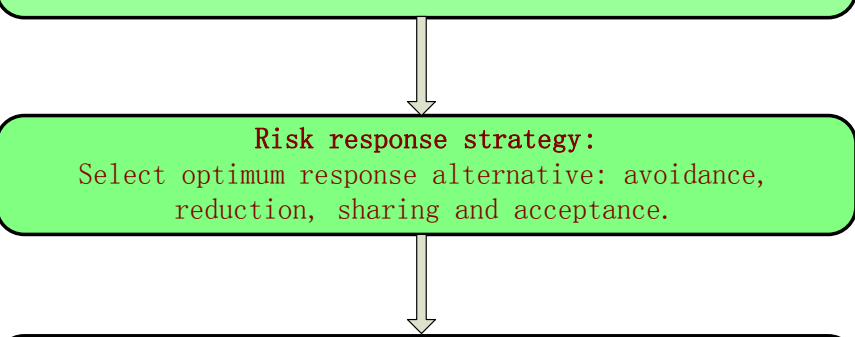

Performance monitor and review:

Process of capture, analysis, and reporting of risk status in relation to performance.

Fig. 2: Risk identification and assessment process. 


\section{PHOTOGRAPHS AND FIGURES}

Integrated management and control of enterprise risk is not strictly a serial process that is made beforehand, it will be adjusted as the situation and environment changing. It is a multidirectional, iterative process in which almost any element can and does influence another. Actions across all above levels are integrated into a systematic, complicated project that embeds a strategic view of risk into all positions of enterprise management, and that gives captains a clear panorama into the challenges and opportunities that risk can brought.

\section{REFERENCES}

[1] COSO. Committee of Sponsoring Organizations of the Treadway Commission. Enterprise Risk ManagementIntegrated Framework: Executive Summary. pp. 2-16, 2004. Available at http://www.aicpa.org.

[2] Sol Plaatje Municipality Risk Management Unit. Enterprise Risk Management Framework. pp.2-12, August 2010.
[3] Committee of Sponsoring Organizations (COSO). Enterprise Risk Management-Integrated Framework: Executive Summary. COSO, New York, 2004. Available at http://www.coso.org

[4] Luca Capriotti, Shinghoi Lee, Matthew Peacock. Real Time Counterparty Credit Risk Management in Monte Carlo. Quantitative Strategies, Investment Banking Division, Credit Suisse Group, Eleven Madison Avenue, New York City, NY 10010-3086, United States of America, pp.1-7,March, 2011.

[5] Reza Tavakoli, Albert C. ReynoldsMonte Carlo simulation of permeability fields and reservoir performance predictions with SVD parameterization in RML compared with EnKF Computational Geosciences January 2011, Volume 15, Issue 1, pp 99-116, Jul 2010.

[6] T. Linder, T. Löfqvist. Monte Carlo simulation of photon transport in a randomly oriented sphere-cylinder scattering medium. Applied Physics B, Volume 105, Issue 3, pp 659664, November 2011.

[7] Joyce A. Curtis, Joseph S. Dailey, Daniel D'Angelo, et al. Transportation Risk Management: International Practices for Program Development and Project Delivery. American Trade Initiatives 3 Fairfield Court Stafford, VA 225541716, pp. 11-16, August. 